\title{
Pristimerin enhances the effect of cisplatin by inhibiting the miR-23a/Akt/GSK3 $\beta$ signaling pathway and suppressing autophagy in lung cancer cells
}

\author{
YINGBING ZHANG ${ }^{1}$, JIQUAN WANG $^{1}$, BEINA HUI $^{1}$, WENZE SUN $^{1}$, BIN LI $^{2}$, FAN \\ $\mathrm{SHI}^{1}, \mathrm{SHAOMIN} \mathrm{CHE}^{1}$, LINYAN CHAI ${ }^{1}$ and LIPING SONG ${ }^{1}$ \\ ${ }^{1}$ Department of Radiation Oncology, The First Affiliated Hospital, Xi'an Jiaotong University, Xi'an, Shaanxi 710061; \\ ${ }^{2}$ Key Laboratory of Resource Biology and Biotechnology in Western China, Ministry of Education, \\ College of Life Science, Northwest University, Xi'an, Shaanxi 710069, P.R. China
}

Received July 3, 2018; Accepted December 31, 2018

DOI: $10.3892 / \mathrm{ijmm} .2019 .4057$

\begin{abstract}
Lung cancer is a common type of cancer with a high mortality rate in China. Cisplatin (Cis) is one of the most effective broad-spectrum chemotherapeutic drugs for the treatment of advanced lung cancer. However, Cis resistance remains an obstacle in the treatment of advanced lung cancer. Pristimerin (Pris), a naturally occurring triterpenoid quinone compound, not only possesses anticancer properties, but also enhances chemosensitivity. Therefore, the present study aimed to investigate whether Pris can enhance the chemosensitivity of lung cancer cells to Cis and identify the underlying mechanism. A Cell Counting kit- 8 and flow cytometry were used to determine cell viability, cell cycle progression and apoptosis in A549 and NCI-H446 cells. Western blotting was used to determine cell apoptosis-related, cell cycle-related and autophagy-related proteins. The results showed that Pris inhibited cell proliferation, and induced $\mathrm{G}_{0} / \mathrm{G}_{1}$ arrest and cell apoptosis in A549 and NCI-H446 cells. The western blotting revealed that Pris effectively synergized with Cis to induce cell apoptosis by inhibiting the microRNA-23a/Akt/glycogen synthase kinase $3 \beta$ signaling pathway and suppressing autophagy. In vivo xenograft experiments confirmed that Pris effectively synergized with Cis to suppress tumor growth. Collectively, these results indicate that Pris synergized with Cis and that this may be a potential therapeutic strategy to overcome lung cancer.
\end{abstract}

Correspondence to: Dr Liping Song, Department of Radiation Oncology, The First Affiliated Hospital, Xi'an Jiaotong University, 277 Yanta West Road, Yanta, Xi'an, Shaanxi 710061, P.R. China E-mail: xaslp@126.com

Key words: lung cancer cells, apoptosis, cell cycle arrest, microRNA-23a, autophagy, Akt, glycogen synthase kinase $3 \beta$

\section{Introduction}

Lung cancer, a common form of cancer, is the leading cause of mortality in China (1). Chemotherapy remains one of the major therapies used to treat advanced lung cancer. Cisplatin (Cis), one of the most effective broad-spectrum anticancer drugs, is a first-line chemotherapeutic drug for the treatment of lung cancer (2). However, Cis resistance seriously influences the rate of success in the treatment of patients with lung cancer (3). Therefore, it is vital to examine less toxic and more effective drugs or chemotherapy-sensitizing agents to overcome Cis resistance in advanced lung cancer.

Pristimerin (Pris), a naturally occurring triterpenoid quinone compound, is extracted from various plant species of the Celastraceae and Hippocrateaceae families (4). Increasing evidence in previous years has shown that Pris can act as a traditional medicine and possesses marked anticancer properties in various cancer cell lines, including esophageal squamous cell carcinoma cells (5), colorectal cancer cells (6), breast cancer cells (7), prostate cancer cells (8), melanoma cells (9), pancreatic cancer cells (10), ovarian cancer cells (11), glioma cells (12) and lung cancer cells (13). It has been reported that Pris exerts anticancer activity via different mechanisms, including the inhibition of nuclear factor $(\mathrm{NF})-\mathrm{\kappa B}$ and $\mathrm{Akt}$ signaling pathways $(6,14)$, induction of cell cycle arrest $(15)$, mitochondrial dysfunction and caspase activation (16). It has also been reported that Pris enhances the chemosensitivity to gemcitabine in pancreatic cancer cells by inhibiting the gemcitabine-induced activation of NF-кB (17). Furthermore, Xie et al (18) demonstrated that Pris enhances the sensitivity of breast cancer cells to adriamycin through suppressing Akt signaling. However, whether Pris can enhance the sensitivity of lung cancer cells to Cis, and by what mechanism this occurs, remain to be elucidated.

The present study aimed to investigate the potential role of Pris in enhancing the anticancer effect of Cis in A549 and NCI-H446 cells in vitro and in A549 cell-transplanted nude mice in vivo. The mechanism underlying the anticancer effects of Pris on enhancing the sensitivity of lung cancer cells to Cis was also examined. 


\section{Materials and methods}

Reagents and antibodies. Pris, Cis and 3-methyladenine (3-MA; an autophagy inhibitor) were obtained from Sigma-Aldrich; Merck KGaA (Darmstadt, Germany). LY294002, a phosphatidylinositol-4,5-bisphosphate 3-kinase (PI3K) inhibitor were obtained from MedChem Express (Monmouth Junction, NJ, USA). The primary antibodies against microtubule-associated protein 1A/1B-light chain 3 (LC3B; cat. no. 4108; 1:2,000), beclin-1 (cat. no. 3738; 1:1,000), cyclin D1 (cat. no. 2922; 1:1,000), phosphorylated (p-)AKT (cat. no. 4058; 1:2,000), AKT (cat. no. 9272; 1:3,000), glycogen synthase kinase $3 \beta$ (GSK-3 $\beta$; cat. no. 12456; 1:1,000), p-GSK3 $\beta$ (Ser9; cat. no. 5558; 1:2,000), phosphatase and tensin homolog (PTEN; cat. no. 9559; 1:1,000), $\beta$-actin (cat. no. 4967; 1:4,000) and poly (ADP-ribose) polymerase (PARP; cat. no. 9542; 1:1,000) were purchased Cell Signaling Technology, Inc. (Danvers, MA, USA). The antibody against p21 (cat. no. 195720; 1:1,000) was purchased from R\&D Systems, Inc. (Minneapolis, MN, USA). Dulbecco's modified Eagle's medium (DMEM) and fetal bovine serum (FBS) were purchased from Gibco (Thermo Fisher Scientific, Inc., Waltham, MA, USA).

Cell culture and cell transfection. The A549 and NCI-H446 human lung carcinoma cell lines were purchased from the Cell Bank of Shanghai Institute of Biochemistry and Cell Biology (Shanghai, China). The cells were cultured in DMEM (Gibco; Thermo Fisher Scientific, Inc.) supplemented with 10\% FBS (Gibco; Thermo Fisher Scientific, Inc.), $100 \mathrm{U} / \mathrm{ml}$ penicillin and $100 \mu \mathrm{g} / \mathrm{ml}$ streptomycin at $37^{\circ} \mathrm{C}$ with $5 \% \mathrm{CO}_{2}$.

The microRNA (miR)-23a inhibitor (5'-GGAAAUCCC UGGCAAUGUGAU-3') and miR-23a negative control (NC, 5'-CAGUACUUUUGUGUAGUACAA-3') were purchased from Shanghai GenePharma Co., Ltd. (Shanghai, China). The A549 and NCI-H446 cells were seeded at $2 \times 10^{5}$ cells $/ \mathrm{ml}$ in 6-well plates and transfected with miR-23a inhibitor and miR-23a-NC using Lipofectamine 2000 (Invitrogen; Thermo Fisher Scientific, Inc.) according to the manufacturer's protocol.

Cell viability assay. Cell viability was detected using the Cell Counting kit-8 (CCK-8) assay (Dojindo Molecular Technologies, Inc., Kumamoto, Japan). The A549 and NCI-H446 cells were seeded into 96-well plates at a density of $1 \times 10^{4}$ cells/well and cultured for $24 \mathrm{~h}$. The cells were treated with indicated concentrations of Pris $(0,10,20,40,60$ and $80 \mu \mathrm{M})$ and $\mathrm{Cis}(0,0.1,0.25,0.5,1$ and $2 \mu \mathrm{M})$ for $24 \mathrm{~h}$. A total of $10 \mu \mathrm{l}$ of CCK-8 solution was then added to each well for an additional $4 \mathrm{~h}$ at $37^{\circ} \mathrm{C}$. The absorbance at $450 \mathrm{~nm}$ was determined using an ELISA Reader (Tecan Group Ltd., Männedorf, Switzerland). This experiment was performed in triplicate.

Cell cycle assay. The A549 and NCI-H446 cells were seeded at $2 \times 10^{5}$ cells $/ \mathrm{ml}$ in 6 -well plates and treated with Pris and Cis for $24 \mathrm{~h}$. The cell cycle phase distribution was detected using a FACSCalibur flow cytometer (BD Biosciences, San Jose, CA, USA) and a Cell Cycle Detection kit (Nanjing KeyGen Biotech Co., Ltd., Nanjing, China). In brief, the cells were trypsinized and fixed with $75 \%$ ethanol overnight at $4{ }^{\circ} \mathrm{C}$. Propidium iodide (PI) was used to stain the DNA of samples for $15 \mathrm{~min}$, and flow cytometry was used to determine cell cycle stage. All experiments were performed at least three times. Data was analyzed with ModFit LT 3.0 (Verity Software House, Topsham, ME, USA).

Cell apoptosis assay. The A549 and NCI-H446 cells were seeded at $2 \times 10^{5}$ cells $/ \mathrm{ml}$ in 6 -well plates and treated with Pris and Cis for $24 \mathrm{~h}$. Cell apoptosis was assessed using an Annexin V-fluorescein isothiocyanate (FITC) Apoptosis Detection kit (Nanjing KeyGen Biotech Co., Ltd.). Briefly, the cells were stained with Annexin V-FITC and PI for $15 \mathrm{~min}$ at room temperature in the dark. The apoptotic cells were then detected on a FACScalibur flow cytometer (BD Biosciences) and analyzed with FlowJo 7.6 software (FlowJo LLC, Ashland, OR, USA). Three independent experiments were performed.

RNA extraction and reverse transcription-quantitative polymerase chain reaction $(R T-q P C R)$ analysis. Total RNA was extracted from the A549 and NCI-H446 cells using TRIzol reagent (Invitrogen; Thermo Fisher Scientific, Inc.). Total RNA $(2 \mu \mathrm{g})$ from the cell samples was reverse transcribed using the Mir-X ${ }^{\mathrm{TM}}$ miRNA First-Strand Synthesis kit (Takara Bio, Inc., Otsu, Japan) according to the manufacturer's protocol. The expression of miR-23a and U6 (Takara Bio, Inc.) was determined using Power SYBR Green PCR Master mix (2X; Applied Biosystems; Thermo Fisher Scientific, Inc.) on an ABI 7500 system (Applied Biosystems; Thermo Fisher Scientific, Inc.). The forward primer of miR-23a was used (5'-ATCACATTGCCAGGGATTTCC-3'). The primers of U6 were obtained from the Mir- ${ }^{\mathrm{TM}}$ miRNA First-Strand Synthesis kit, and U6 was used as a control for normalization. The thermocycling conditions were as follows: $95^{\circ} \mathrm{C}$ for $10 \mathrm{~min}$, followed by 40 cycles of $95^{\circ} \mathrm{C}$ for $10 \mathrm{sec}, 60^{\circ} \mathrm{C}$ for $20 \mathrm{sec}$ and $72^{\circ} \mathrm{C}$ for $10 \mathrm{sec}$. The relative level of miR-23a was calculated using the $2^{-\Delta \Delta \mathrm{Cq}}$ method (19).

In vivo xenograft tumor model. Male BALB/c nude mice (8 weeks old; 18-20 g) were obtained from the Animal Experiment Center of Xi'an Jiaotong University (Xi'an, China). All mice were housed in a specific pathogen free (SPF) animal at $20-26^{\circ} \mathrm{C}$ and $40-70 \%$ humidity with a $12 \mathrm{~h}$ light/dark cycle. Food and water were available ad libitum. The experiments were approved by the Laboratory Animal Care Committee of Xi'an Jiaotong University (approval no. XJTULAC2018-527). The xenograft tumor model was performed as previously described (20-22). Briefly, A549 cells $\left(5 \times 10^{6}\right.$ cells $/ \mathrm{ml}$ in $\left.0.2 \mathrm{ml}\right)$ were subcutaneously injected into the right flanks of BALB/c nude mice. The mice were divided into four groups $(n=3$ per group): Saline control group, Pris $(0.8 \mathrm{mg} / \mathrm{kg})$ treatment group, Cis $(2 \mathrm{mg} / \mathrm{kg})$ treatment group, and combined Pris + Cis treatment group. The xenograft tumors were developed for 14 days post-injection. Following this, the nude mice were treated with Pris $(0.8 \mathrm{mg} / \mathrm{kg})$ and Cis $(2 \mathrm{mg} / \mathrm{kg})$ for 14 days. Tumor volume was calculated as follows: Tumor volume $\left(\mathrm{mm}^{3}\right)=$ long diameter of the tumor $x$ short diameter of the tumor ${ }^{2} / 2$. On the last day of the experiment (day 28), the tumor samples were collected and weighed. Hematoxylin and eosin (H\&E) staining and terminal deoxynucleotidyl-transferase-mediated 
dUTP nick end labeling (TUNEL) assays were used to examine morphology and cell apoptosis in the xenografted lung tumors. Images were captured using a Olympus BX53 microscope (Olympus Corporation, Tokyo, Japan).

Western blotting. Following treatment with Pris and Cis, the cells were lysed in lysis buffer for western blot detection, as described previously (23). Briefly, the cell samples were lysed on ice with radioimmunoprecipitation assay buffer containing protease inhibitors and the proteins were quantified with Bicinchoninic Acid Protein Assay kit (Thermo Fisher Scientific, Inc.). Proteins (40 $\mu \mathrm{g} /$ well) were separated on $6-12 \%$ gels using SDS-PAGE and protein was transferred onto nitrocellulose membranes (Pall Life Sciences, Port Washington, NY, USA) and the membranes were blocked with $5 \%$ nonfat milk for $2 \mathrm{~h}$, followed by incubation with anti-cyclin D1, anti-P21, anti-beclin1, anti-LC3B, anti-p-AKT anti-AKT, anti-PTEN, anti-p-GSK $3 \beta$, anti-GSK-3 $\beta$, anti-PARP and anti- $\beta$-actin antibodies at $4^{\circ} \mathrm{C}$ overnight. Membranes were then incubated with horseradish peroxidase (HRP)-conjugated anti-mouse IgG (cat. no. 7076; 1:20,000) and HRP-conjugated anti-rabbit IgG (cat. no. 7074; 1:20,000; both Cell Signaling Technology, Inc.) secondary antibodies for $2 \mathrm{~h}$ at $25^{\circ} \mathrm{C}$. The proteins were visualized using SuperSignal West Pico Chemiluminescent Substrate (Pierce; Thermo Fisher Scientific, Inc.) and exposed to X-ray film. Densitometry was performed using ImageJ version $1.38 \mathrm{x}$ software (National Institutes of Health, Bethesda, MD, USA) and the resulting data analyzed using GraphPad Prism 6.0 (GraphPad Software, Inc., La Jolla, CA, USA).

Statistical analysis. All data are presented as the mean \pm standard deviation. Data were analyzed using GraphPad Prism 6.0 (GraphPad Software, Inc., La Jolla, CA, USA). Differences between groups were determined by one-way analysis of variance followed by Dunnett's or Tukey's post hoc tests. $\mathrm{P}<0.05$ was considered to indicate a statistically significant difference.

\section{Results}

Pris and Cis inhibit cell growth in A549 and NCI-H446 cells. To investigate the effects of Pris and Cis on cell proliferation, the A549 and NCI-H446 cells were exposed to different concentrations of Pris or Cis for $24 \mathrm{~h}$, and cell viability was investigated using a CCK-8 assay. As shown in Fig. 1A and B, Pris or Cis significantly inhibited the growth of A549 and NCI-H446 cells in a concentration-dependent manner. According to these results, experiments were performed to investigate whether the combined treatment of Pris + Cis significantly promoted the inhibition of A549 and NCI-H446 cell viability in comparison with Pris or Cis treatment alone. As shown in Fig. 1C, the combination treatment significantly enhanced the inhibitory effect on cell viability compared with Pris or Cis treatment alone in the A549 and NCI-H446 cell lines. These results indicated that Pris may significantly increase the sensitivity to Cis by inhibiting cell viability in A549 and NCI-H446 cells.

Pris and Cis induce cell cycle arrest in A549 and NCI-H446 cells. It is well known that cell cycle arrest may lead to cell growth inhibition. Therefore, the effect of Pris and Cis on cell cycle arrest in A549 and NCI-H446 cells was detected using flow cytometry. As shown in Fig. 2A and B, the percentage of cells at $G_{0} / G_{1}$ phase significantly increased with Pris treatment and the percentage of cells at $\mathrm{S}$ phase significantly increased with Cis treatment in A549 and NCI-H446 cells. Furthermore, it was observed that the combination treatment significantly elevated the percentage of cells in the $\mathrm{G}_{0} / \mathrm{G}_{1}$ phase compared with Cis treatment alone in the A549 and NCI-H446 cells (Fig. 2A and B). These data indicated that $\mathrm{G}_{0} / \mathrm{G}_{1}$ phase arrest may contribute to enhancing cell growth inhibition induced by Cis.

The $\mathrm{G}_{0} / \mathrm{G}_{1}$-related proteins were examined by western blotting. As shown in Fig. 2C, Pris or Cis treatment alone markedly upregulated the expression level of p21 but downregulated the expression of cyclin D1 compared with the control group. The combination treatment markedly upregulated the expression level of p21 but downregulated the expression of cyclin D1 compared with either Pris or Cis treatment alone in A549 and NCI-H446 cells. These results indicated that Pris increased the antiproliferative effect of Cis in A549 and NCI-H446 cells via upregulating p21 and downregulating cyclin D1.

Pris and Cis induce cell apoptosis in A549 and NCI-H446 cells. To further evaluate the effects of Pris and Cis on cell growth inhibition, cell apoptosis was detected in A549 and NCI-H446 cells using flow cytometry. As shown in Fig. 3A and B, Pris, Cis and the combination treatment significantly induced cell apoptosis in the A549 and NCI-H446 cells. Combination treatment with Pris and Cis significantly increased the number of apoptotic cells compared with either drug alone in the A549 and NCI-H446 cells (Fig. 3A and B). To further evaluate the effect of apoptosis induced by Pris and Cis, the apoptosis-related protein PARP was analyzed using western blotting. As shown in Fig. 3C, Pris, Cis and the combination treatment markedly upregulated the expression level of cleaved PARP. Therefore, these results showed that Pris markedly enhanced Cis-induced apoptosis in the A549 and NCI-H446 cells.

Pris enhances Cis-induced apoptosis by suppressing the Akt/GSK3ß signaling pathway in A549 and NCI-H446 cells. To further elucidate the molecular mechanism of Pris and Cis-induced cell apoptosis in A549 and NCI-H446 cells, the expression of proteins related to the Akt/GSK3 signaling pathway were detected in A549 and NCI-H446 cells using western blotting. As shown in Fig. 4A, the levels of p-Akt and p-GSK $3 \beta$ were markedly inhibited by Pris, Cis and the combination treatments. Furthermore, the combination treatment of Pris + Cis markedly inhibited the phosphorylation of Akt and GSK3 $\beta$ compared with either drug alone in the A549 and NCI-H446 cells (Fig. 4A). LY294002, a type of PI3K inhibitor, markedly inhibited the levels of p-GSK3 $\beta$ and p-Akt in A549 and NCI-H446 cells (Fig. 4B). In addition, as shown in Fig. 4C, LY294002 in combination with Cis enhanced the inhibitory effect on cell viability compared with Cis alone in the A549 and NCI-H446 cell lines. These results indicated that Pris enhanced the sensitivity of A549 and NCI-H446 cells to Cis via suppressing Akt/GSK3 $\beta$ signaling. 

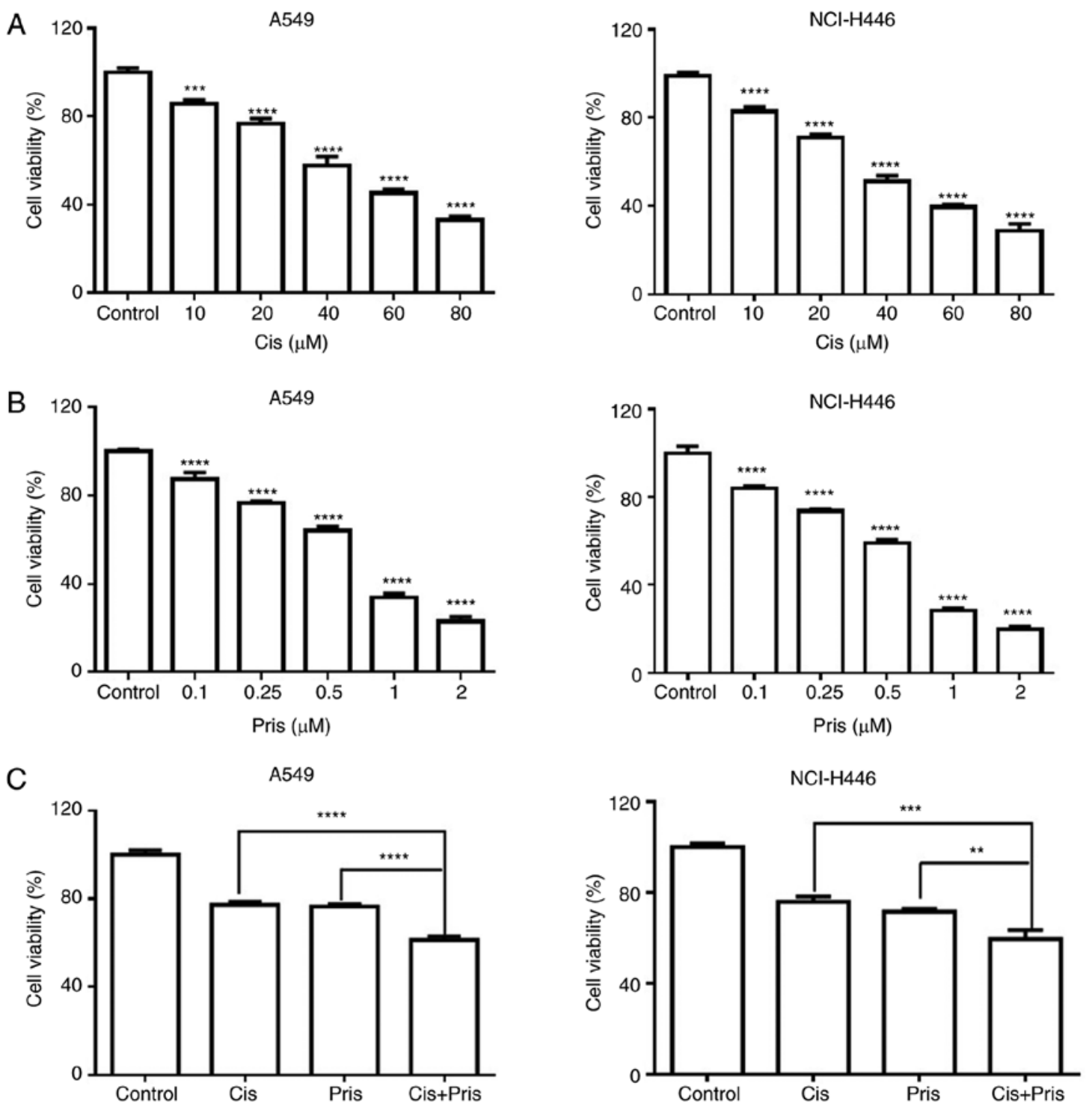

Figure 1. Pris enhances the inhibition of proliferation caused by Cis in lung cancer cell lines. A549 and NCI-H446 cells were treated with various concentrations of (A) Cis, and (B) Pris for $24 \mathrm{~h}$, and cell viability was determined using a CCK-8 assay. ${ }^{* * * * *} \mathrm{P}<0.001$ vs. control. (C) A549 and NCI-H446 cells treated with Pris $(0.25 \mu \mathrm{M})$ and/or Cis $(20 \mu \mathrm{M})$ for $24 \mathrm{~h}$. Cell viability was determined using a CCK-8 assay. Data are presented as the mean \pm standard deviation of three independent experiments. ${ }^{* *} \mathrm{P}<0.01,{ }^{* * * *} \mathrm{P}<0.001,{ }^{* * * *} \mathrm{P}<0.0001$. Cis, cisplatin; Pris, pristimerin; CCK- 8 , Cell Counting kit-8.

Pris enhances Cis-induced apoptosis through the downregulation of miR-23a in A549 and NCI-H446 cells. miR-23a has been indicated to be as an important regulator of PTEN/Akt signaling $(24,25)$. Therefore, the present study investigated whether miR-23a contributed to the sensitivity of A549 and NCI-H446 cells to Cis via the PTEN/Akt signaling pathway. As shown in Fig. 5A, Pris significantly downregulated the expression level of miR-23a in the A549 and NCI-H446 cells. To further examine the effect of miR-23a on the PTEN/Akt signaling pathway, the protein expression of GSK3 $\beta$, Akt and PTEN in A549 and NCI-H446 cells were examined using western blotting. As shown in Fig. 5B, the miR-23a inhibitor markedly upregulated the expression level of PTEN and downregulated the phosphorylation of Akt and GSK $3 \beta$ compared with that in the blank control cells. In addition, the results of the flow cytometry revealed that combination treatment with miR-23a inhibitor and Cis significantly increased the number of apoptotic A549 and NCI-H446 cells compared with the Cis treatment alone (Fig. 5C and D). These results indicated that Pris enhanced the sensitivity of A549 and NCI-H446 cells to Cis via suppressing the miR-23a/PTEN/Akt signaling pathway.

Pris enhances Cis-induced apoptosis via suppressing autophagy in A549 and NCI-H446 cells. Numerous studies have demonstrated that autophagy is associated with the regulation of cell apoptosis induced by antitumor drugs (26-28). To evaluate whether autophagy is involved in increasing the apoptosis of Cis-treated A549 and NCI-H446 cells, the protein expression levels of LC3B and beclin-1 were detected by western blotting. As shown in Fig. 6A, the expression levels of LC3BII and beclin-1 were markedly downregulated by Pris treatment with the blank control cells. In addition, flow cytometry revealed that combination treatment with 3-MA (an autophagy inhibitor) and Cis significantly increased the number of apoptotic cells compared with Cis treatment alone 
A
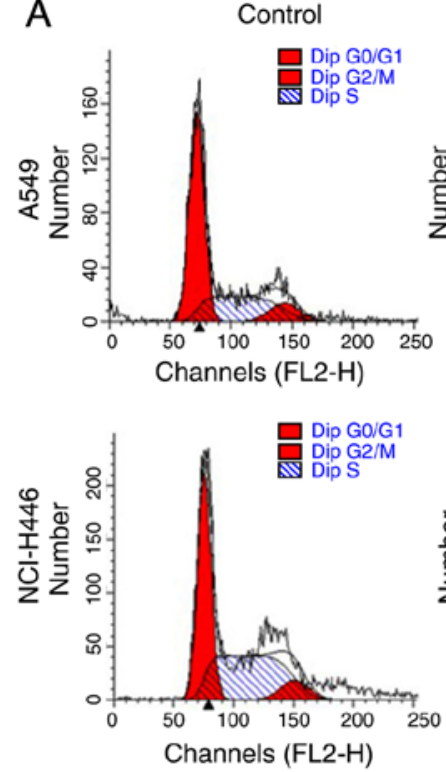

Cis
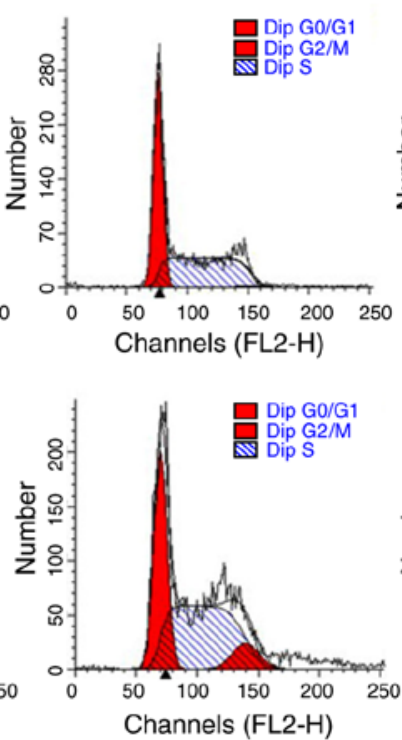

B

A549

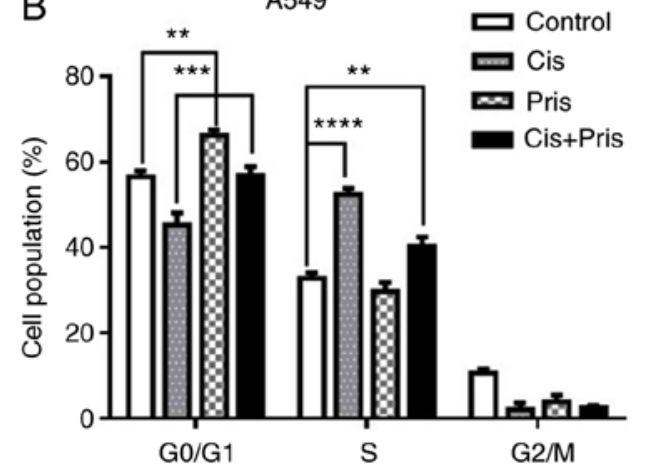

C

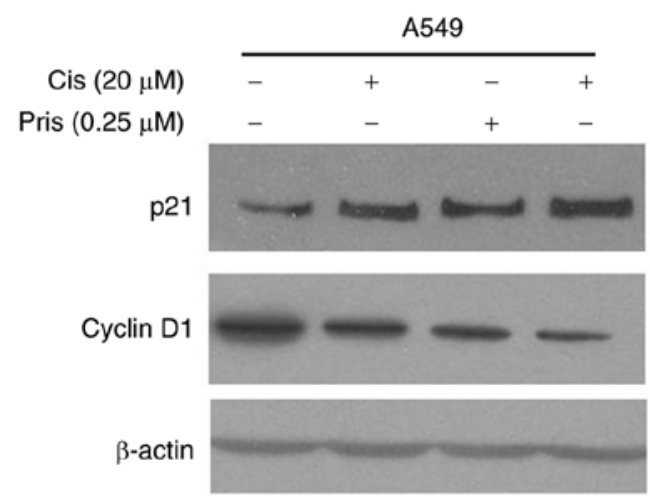

Pris
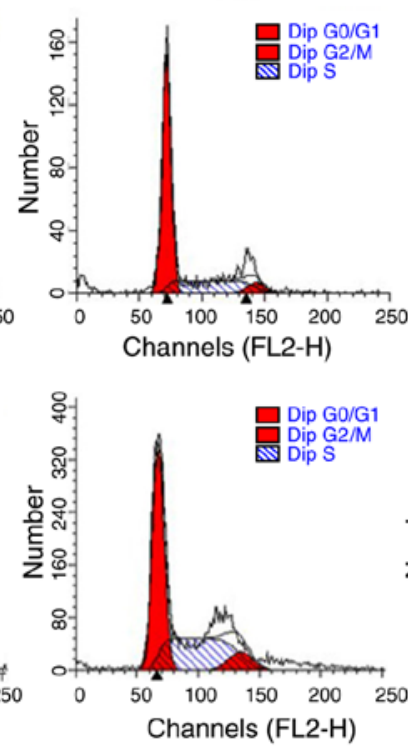

$\mathrm{NCl}-\mathrm{H} 446$
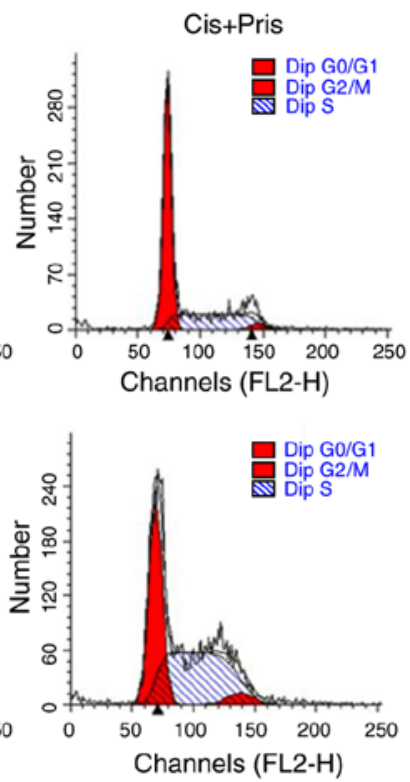
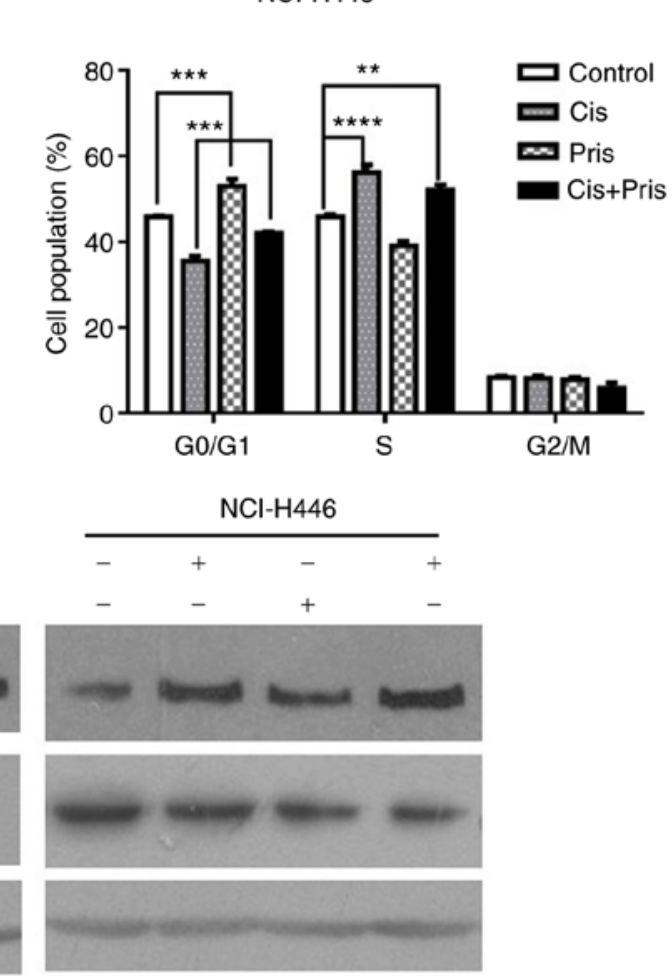

Figure 2. Effects of Pris and/or Cis treatment on the cell cycle of A549 and NCI-H446 cells. (A) A549 and NCI-H446 cells were treated with Pris (0.25 $\mu \mathrm{M})$ and/or Cis $(20 \mu \mathrm{M})$ for $24 \mathrm{~h}$, and cell cycle distribution was analyzed using flow cytometry. (B) Graphs showing results of flow cytometry. Data are presented as the mean \pm standard deviation of three independent experiments. ${ }^{* *} \mathrm{P}<0.01,{ }^{* * * *} \mathrm{P}<0.001,{ }^{* * * * *} \mathrm{P}<0.0001$. (C) A549 and NCI-H446 cells treated with Pris $(0.25 \mu \mathrm{M})$ and/or Cis $(20 \mu \mathrm{M})$ for $12 \mathrm{~h}$. The protein expression levels of cyclin D1 and p21 were examined using western blotting. $\beta$-actin served as a loading control. Cis, cisplatin; Pris, pristimerin.

in the A549 and NCI-H446 cells (Fig. 6B and C). These results indicated that Pris enhanced the sensitivity of A549 and NCI-H446 cells to Cis via suppressing autophagy.

Pris enhances the anticancer activity of Cis in vivo. To evaluate the synergistic effect of Pris and Cis, an in vivo xenograft model was established. A549 cells were injected into BALB/c nude mice. The xenograft tumors were developed for 14 days post-injection and the nude mice were then treated with Pris $(0.8 \mathrm{mg} / \mathrm{kg})$ and Cis $(2 \mathrm{mg} / \mathrm{kg})$ for a further 14 days. As shown in Fig. 7A-D, the tumor volumes and weights in the Pris treatment group, Cis treatment group and combination treatment group were lower compared with those in the control group. Furthermore, combination treatment significantly attenuated tumor volume and weight compared with either drug alone. However, no significant changes in body weight were observed among the four experimental groups (Fig. 7E). The H\&E staining and TUNEL analysis showed that apoptotic 

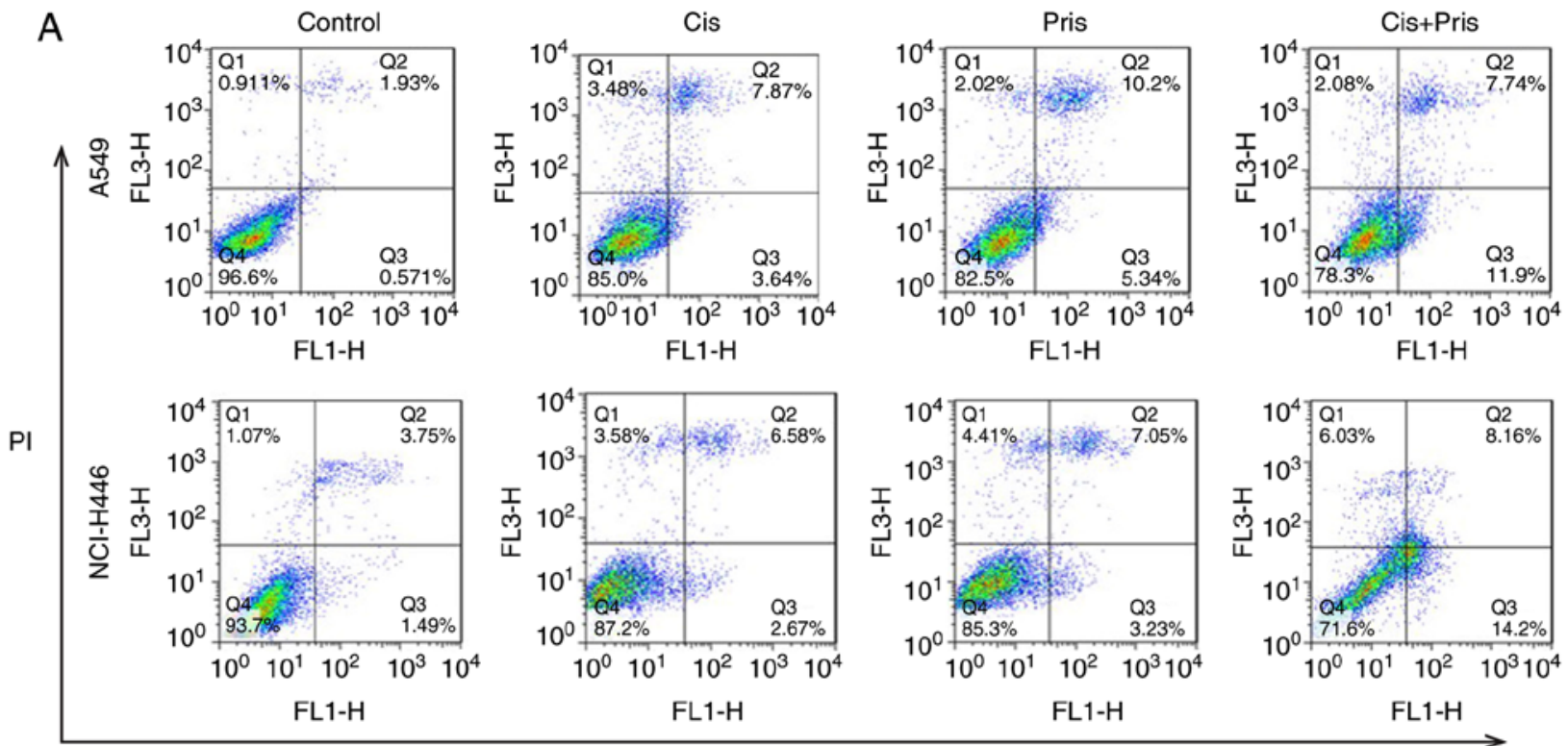

B
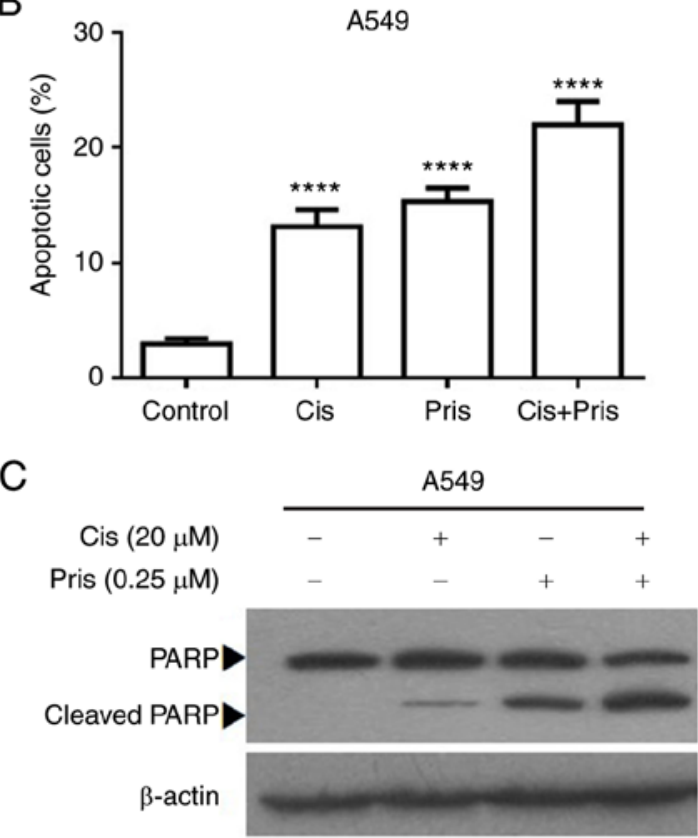

Annexin V
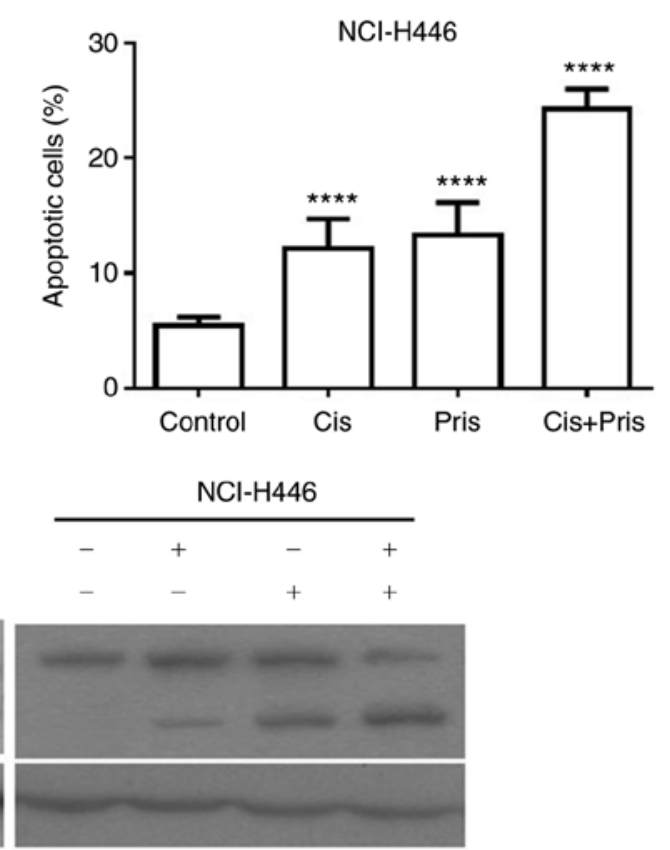

Figure 3. Pris enhances the apoptosis of Cis-induced lung cancer cells. (A) A549 and NCI-H446 cells were treated with Pris ( $0.25 \mu \mathrm{M})$ and/or Cis (20 $\mu \mathrm{M})$ for $24 \mathrm{~h}$. Cell apoptosis was analyzed using flow cytometry. (B) Graphs showing the results of flow cytometry. Data are presented as the mean \pm standard deviation of three independent experiments. ${ }^{* * * *} \mathrm{P}<0.0001$. (C) A549 and NCI-H446 cells were treated with Pris $(0.25 \mu \mathrm{M})$ and/or Cis $(20 \mu \mathrm{M})$ for $12 \mathrm{~h}$. The protein expression of PARP was examined using western blotting. $\beta$-actin served as a loading control. ${ }^{* * * *} \mathrm{P}<0.0001$ vs. control. Cis, cisplatin; Pris, pristimerin; PI, propidium iodide; PARP, poly (ADP-ribose) polymerase.

cells in the tumor tissues were markedly increased following Pris and Cis combination treatment compared with treatment with either drug alone (Fig. 7F). In addition, western blotting revealed that combination treatment with Pris and Cis markedly inhibited the phosphorylation of Akt and GSK3 $\beta$ compared with treatment with either drug alone in A549 tumor tissues (Fig. 7G-I). Taken together, the results suggested that Pris and Cis acted synergistically against lung cancer in vivo.

\section{Discussion}

Lung cancer is one of the most common malignancies worldwide, and mortality rates in China are the highest globally. Although Cis is a broad-spectrum anticancer drug that is often used in the treatment of lung cancer, chemoresistance critically limits the efficacy of treatment. Therefore, the development of novel anticancer drugs to improve the chemosensitivity of lung cancer cells to Cis has become a necessity. In the present study, the role of Pris in the sensitization of A549 and NCI-H446 cells to Cis-induced cell death was investigated. The results showed that A549 and NCI-H446 cells treated with a combination of Pris and Cis enhanced cell growth inhibition and cell apoptosis compared with cells treated with either drug alone and untreated cells. It was further validated that Pris enhanced tumor growth inhibition and cell apoptosis in combination with Cis in an in vivo xenograft model, which 
A
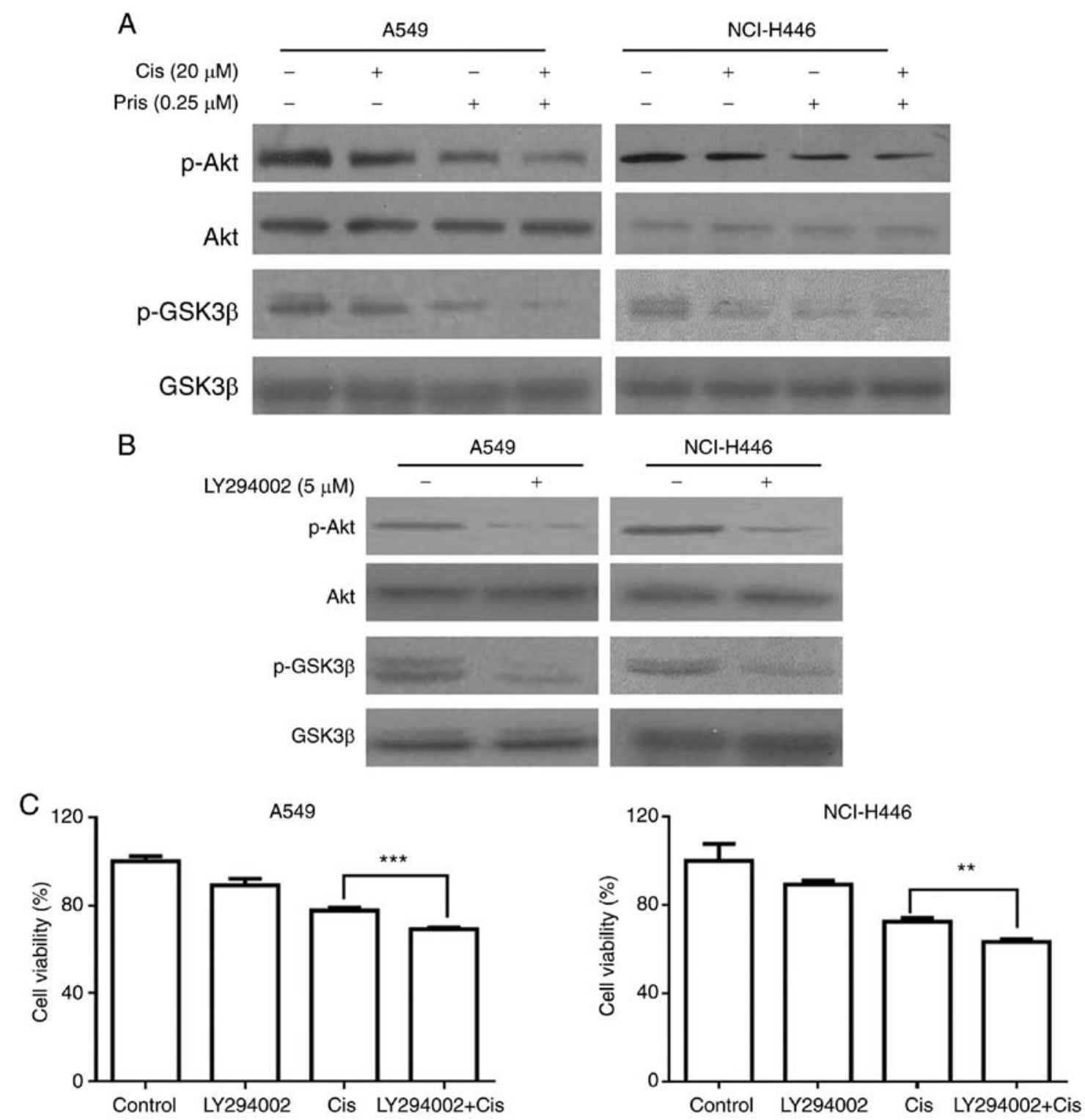

Figure 4. Pris enhances the apoptosis of Cis-induced lung cancer cells via the inhibition of Akt/GSK3 $\beta$ signaling. (A) A549 and NCI-H446 cells treated with Pris $(0.25 \mu \mathrm{M})$ and/or Cis $(20 \mu \mathrm{M})$ for $12 \mathrm{~h}$. Western blotting was used to detect the protein expression levels of p-Akt, Akt, p-GSK3 $\beta$ and GSK3 $\beta$. (B) A549 and NCI-H446 cells were treated with LY294002 $(5 \mu \mathrm{M})$ for $12 \mathrm{~h}$. The protein expression of p-Akt, Akt, p-GSK3 $\beta$ and GSK3 $\beta$ were analyzed by western blotting. (C) A549 and NCI-H446 cells were pretreated with LY294002 $(5 \mu \mathrm{M})$ for $1 \mathrm{~h}$, followed by treatment with Pris $(0.25 \mu \mathrm{M})$ and/or Cis $(20 \mu \mathrm{m})$ for $24 \mathrm{~h}$. Cell viability was measured using a Cell Counting kit- 8 assay. ${ }^{* *} \mathrm{P}<0.01,{ }^{* * *} \mathrm{P}<0.001$. Cis, cisplatin; Pris, pristimerin; GSK, glycogen synthase kinase $3 \beta$; $\mathrm{p}-$, phosphorylated.

was consistent with the findings in vitro. In addition, it was found that combination treatment significantly induced $G_{0} / G_{1}$ phase arrest compared with Cis treatment alone. It was also demonstrated that Pris enhanced the sensitivity of A549 and NCI-H446 cells to Cis through suppressing autophagy and inhibiting miR-23a/Akt/GSK3 $\beta$ signaling.

Numerous studies have shown that cell cycle arrest induced by anticancer drugs is an effective strategy for inhibiting cancer cell proliferation $(29,30)$. A previous study showed that Cis may inhibit cell proliferation via triggering $\mathrm{S}$ phase arrest in A549 cells $(31,32)$. Pris, a potential anticancer drug, has been reported to enhance the chemosensitivity of pancreatic cancer cells to gemcitabine via inducing $\mathrm{G}_{0} / \mathrm{G}_{1}$ phase arrest (17). Yousef et al (15) also reported that Pris exerted anticancer activity in colorectal cancer cells by inducing $G_{0} / G_{1}$ phase arrest. The results of the present study demonstrated that Pris or Cis significantly induced $\mathrm{G}_{0} / \mathrm{G}_{1}$ phase arrest or $\mathrm{S}$ phase arrest in A549 and NCI-H446 cells. Compared with Cis alone, the combination treatment of Pris and Cis significantly increased $\mathrm{G}_{0} / \mathrm{G}_{1}$ phase arrest in the A549 and NCI-H446 cells. Notably, the cell cycle is regulated by multiple molecular processes, including cyclin-dependent kinase (CDK)-regulated processes. Previous results have demonstrated that a reduction in the protein expression of cyclin D1 may inhibit the $G_{0} / G_{1}$ to $\mathrm{S}$ phase transition $(33,34)$. Additionally, it has been reported that p21, a crucial CDK inhibitor, may promote $G_{0} / G_{1}$ phase arrest by downregulating the expression of CDK complexes $(35,36)$. In the present study, it was found that Pris treatment alone markedly upregulated the expression level of p21 but downregulated the expression of cyclin D1 compared with the control group. Furthermore, combination treatment markedly upregulated the expression level of p21 but downregulated the 

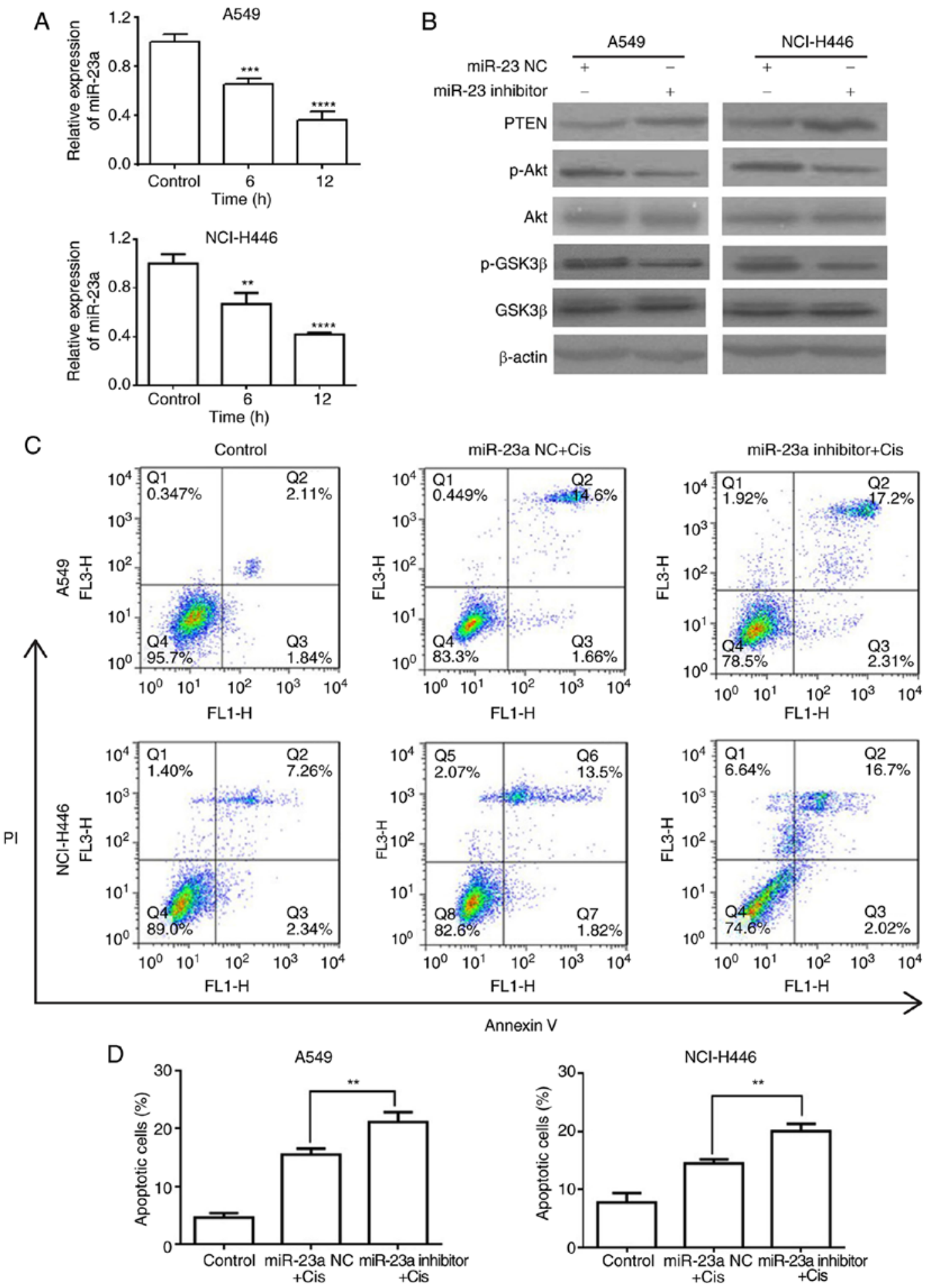

Annexin V

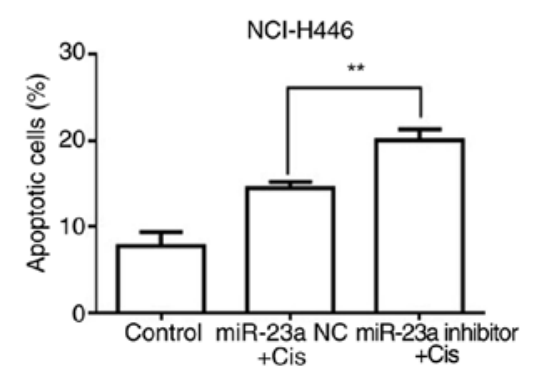

Figure 5. Pris enhances the apoptosis of Cis-induced lung cancer cells via the downregulation of miR-23a. (A) A549 and NCI-H446 cells were treated with Pris $(0.25 \mu \mathrm{M})$ for 0,6 and $12 \mathrm{~h}$. Relative expression levels of miR-23a were measured using reverse transcription-quantitative polymerase chain reaction analysis. Data are presented as the mean \pm standard deviation of three independent experiments. ${ }^{* *} \mathrm{P}<0.01,{ }^{* * * *} \mathrm{P}<0.001,{ }^{* * * *} \mathrm{P}<0.0001$ vs. control. (B) A549 and NCI-H446 cells were transfected with miR-23a NC or inhibitor for $48 \mathrm{~h}$. Western blotting was used to detect the protein expression of PTEN, p-Akt, Akt, p-GSK3 $\beta$ and GSK3 $\beta$. $\beta$-actin served as a loading control. (C) A549 and NCI-H446 cells were transfected with miR-23a NC or inhibitor for 48 h, followed by treatment with or without Cis $(20 \mu \mathrm{M})$ for $24 \mathrm{~h}$. Cell apoptosis was analyzed using flow cytometry. (D) Graphs showing results of flow cytometry. Data are presented as the mean \pm standard deviation of three independent experiments. ${ }^{* *} \mathrm{P}<0.01$. Cis, cisplatin; Pris, pristimerin; PTEN, phosphatase and tensin homolog; miR, microRNA; NC, negative control; GSK, glycogen synthase kinase 3 $\beta$; p-, phosphorylated; PI, propidium iodide.

expression of cyclin D1 compared with Cis treatment alone in the A549 and NCI-H446 cell lines. These data suggested that the downregulation of cyclin D1 and upregulation of p21 may be potential mechanisms that contributes to Pris enhancing Cis-induced cell growth inhibition in A549 and NCI-H446 cells.
Anticancer drug-induced apoptosis has been reported as an effective strategy in anticancer therapy (37). Cis is a broad-spectrum anticancer drug that can induce cell apoptosis in a variety of cancer cells. Furthermore, increasing evidence has demonstrated that Pris can induce the apoptosis of cells in various 
A

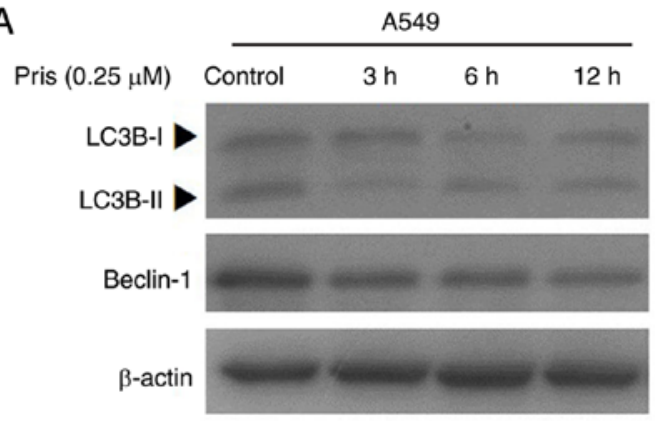

B
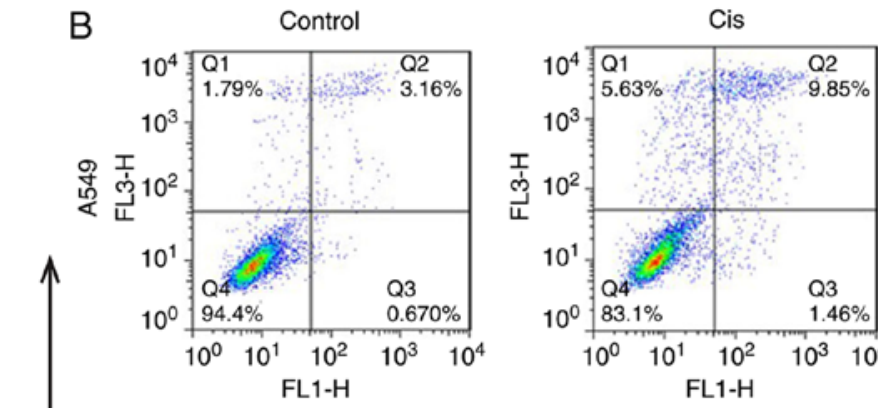
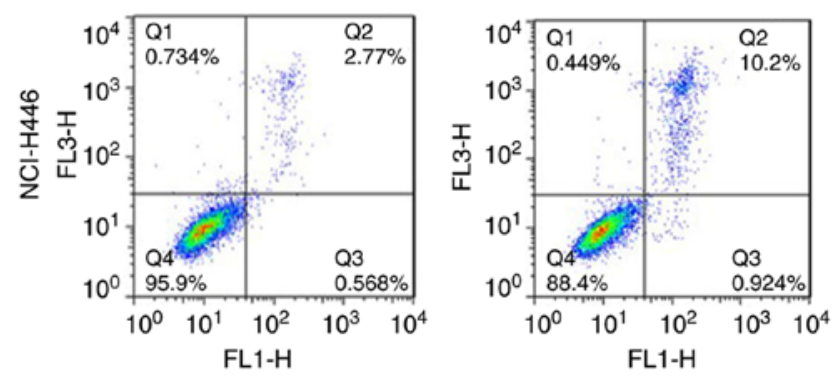

Annexin V

\section{C}

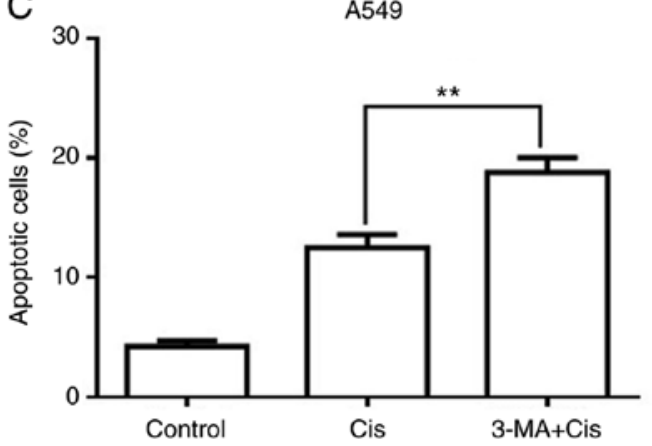

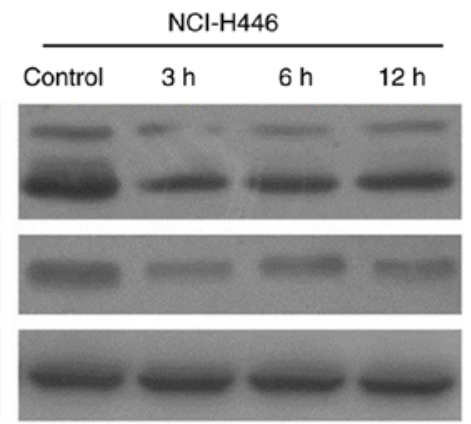
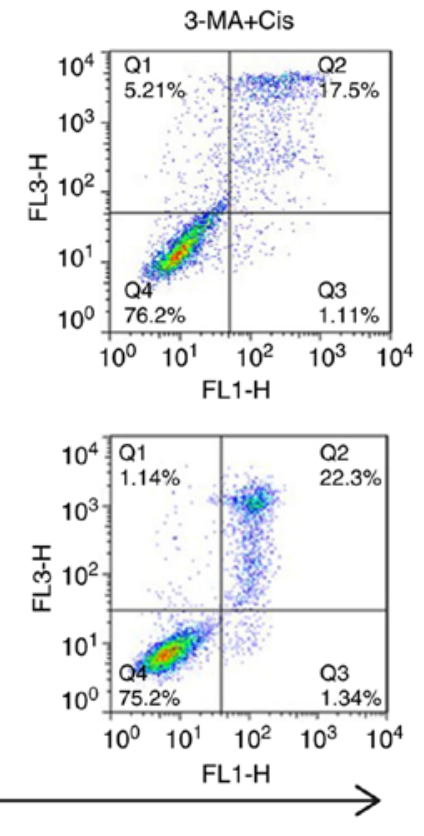

$\mathrm{NCl}-\mathrm{H} 446$

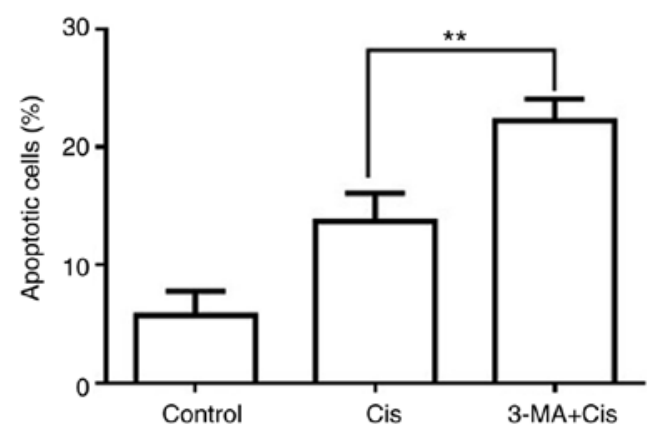

Figure 6. Pris enhances the apoptosis of Cis-induced lung cancer cells via the inhibition of autophagy. (A) A549 and NCI-H446 cells were treated with Pris $(0.25 \mu \mathrm{M})$ for $0,3,6$ and $12 \mathrm{~h}$. The protein expression levels of LC3B and beclin-1 were measured using western blotting. (B) A549 and NCI-H446 cells were pretreated with 3-MA $(5 \mathrm{mM})$ for $2 \mathrm{~h}$, which was followed by treatment with or without Cis $(20 \mu \mathrm{M})$ for $24 \mathrm{~h}$. Cell apoptosis was analyzed using flow cytometry. (C) Graphs showing results of flow cytometry. Data are presented as the mean \pm standard deviation of three independent experiments. ${ }^{* *} \mathrm{P}<0.01$. Cis, cisplatin; Pris, pristimerin; 3-MA, 3-methyladenine; LC3B, microtubule-associated protein 1A/1B-light chain 3; PI, propidium iodide.

types of cancer, including breast cancer (7), colorectal cancer (15), pancreatic cancer (17) and prostate cancer (38). In the present study, it was observed that Pris, Cis and combination treatments significantly induced the apoptosis of A549 and NCI-H446 cells and in the in vivo xenograft model. The combination treatment of Pris and Cis significantly increased the number of apoptotic cells compared with either drug alone in vitro and in vivo. The results of the western blotting also showed that the Pris, Cis and the combination treatment markedly upregulated the expression level of cleaved PARP in the A549 and NCI-H446 cells. Combination treatment with Pris and Cis markedly increased the expression of cleaved PARP compared with either drug alone in A549 and NCI-H446 cells. These results indicated that the upregulation of cleaved PARP contributed to Pris enhancing Cis-induced cell apoptosis.

Cell apoptosis is induced by multiple signaling pathways, including the Akt signaling pathway which has a central role in cell apoptosis. Therefore, anticancer drugs often induce cancer apoptosis through inhibiting the AKT signaling pathway $(39,40)$. It has been reported that Pris is a potential anticancer drug that can induce apoptosis in pancreatic cancer cells and colorectal cancer cells $(15,41)$. Bi et al $(42)$ reported that metformin synergistically 
A
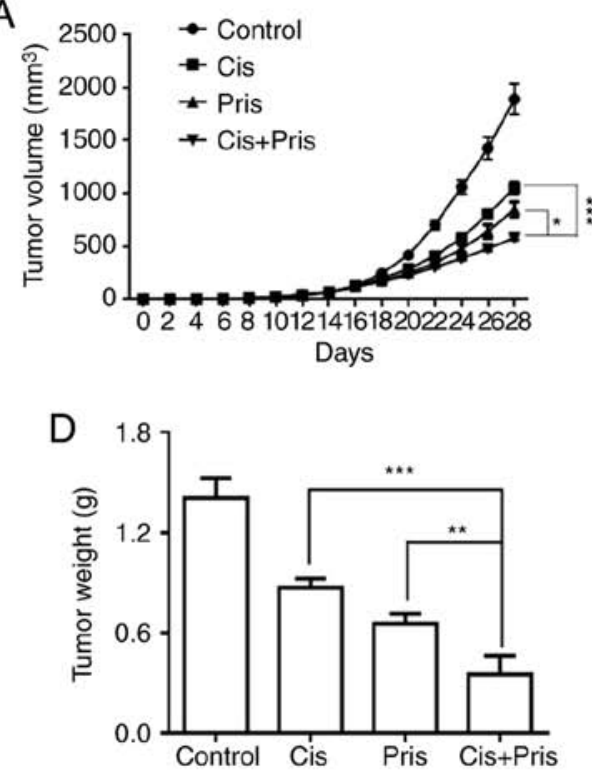

$\mathrm{F}$
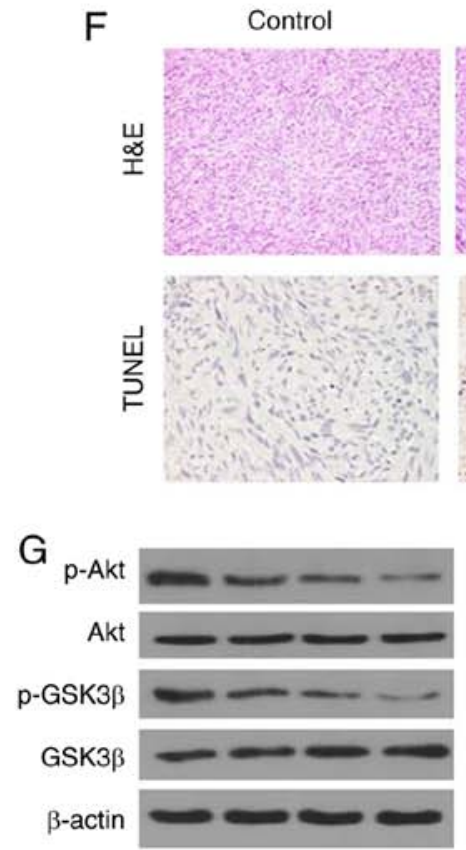

Cis

$\mathrm{H}$
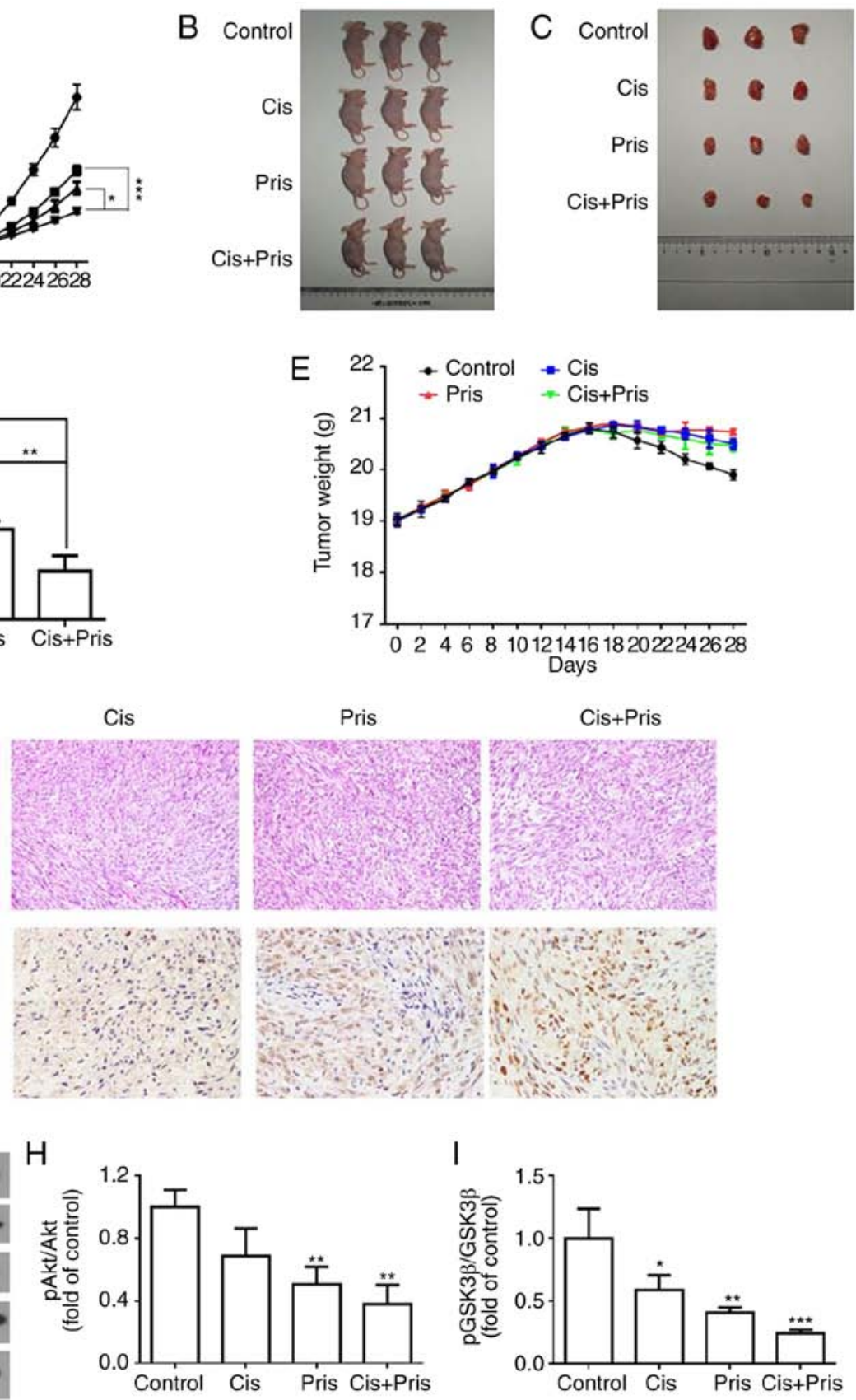

Pris

Cis+Pris
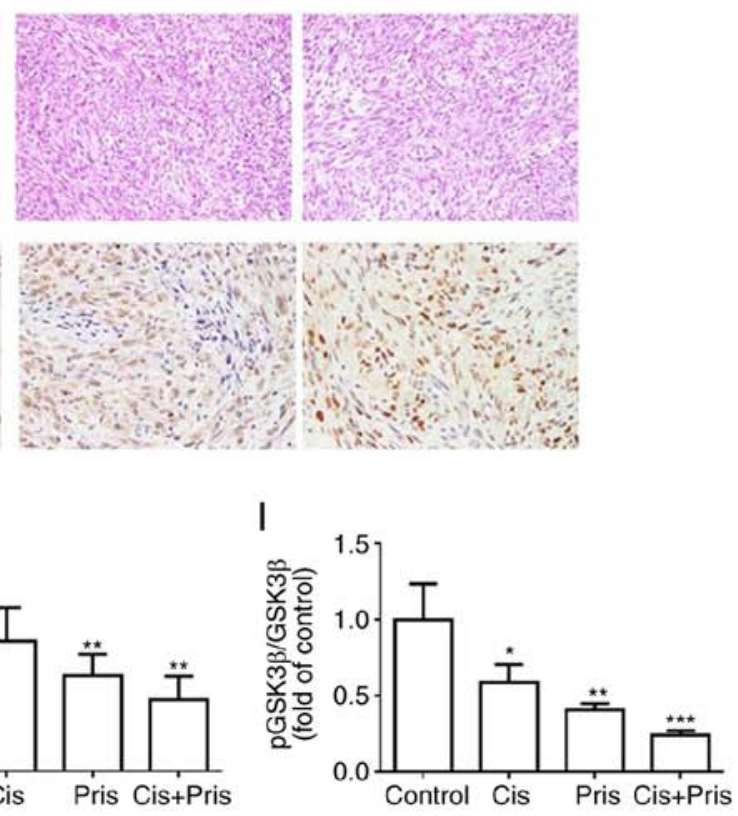

Figure 7. Pris combined with Cis inhibits lung cancer xenograft growth in vivo. (A) Tumor volumes in the Pris-, Cis- and combination-treated BALB/c nude mice were measured every 2 days for 28 days. (B) Mice and (C) tumors of the tumor xenograft models of the four groups. A549 cells were injected into BALB/c nude mice. At 14 days post-tumor injection, nude mice were treated with Pris $(0.8 \mathrm{mg} / \mathrm{kg}$ ) and Cis $(2 \mathrm{mg} / \mathrm{kg})$ for 14 days. (D) Tumor weights for each group were measured on the last day of the experiment (day 28). (E) Body weights of the Pris-, Cis- and combination-treated BALB/c nude mice were measured once every 2 days for 28 days. (F) Tumor samples of each group were subjected to H\&E staining (magnification, $\mathrm{x} 200$ ) and TUNEL assays (magnification, $\mathrm{x} 400$ ) on the last day of the experiment (day 28). (G) Western blotting was used to examine the effect of Pris and/or Cis on the protein expression levels of (H) p-Akt and Akt, and (I) p-GSK3 $\beta$ and GSK3 $\beta$ in the tumor samples (day 28). Data are presented as the mean \pm standard deviation $(\mathrm{n}=3)$. ${ }^{*} \mathrm{P}<0.05$, ${ }^{* *} \mathrm{P}<0.01$, ${ }_{* * * *} \mathrm{P}<0.001$ vs. control. Cis, cisplatin; Pris, pristimerin; H\&E, hematoxylin and eosin; TUNEL, terminal deoxynucleotidyl-transferase-mediated dUTP nick end labeling; GSK, glycogen synthase kinase $3 \beta ;$ p-, phosphorylated.

enhances Cis-induced apoptosis via increasing the inhibition of Akt activity mediated by cisplatin. Liao et al (43) also revealed that matrine enhances the pro-apoptotic ability of Cis in urothelial bladder cancer cells through increasing the inhibition of Akt activity mediated by Cis (43). In the present study, Pris, Cis and the combination treatment markedly inhibited the phosphorylation of Akt, and the combination treatment markedly inhibited the phosphorylation of Akt compared with either drug alone. To further evaluate whether the Akt signaling pathway is involved in enhancing Cis-induced apoptosis, the A549 and NCI-H446 cells were treated with LY294002 and Cis. The effect of Cis combined with LY294002 on the viability of A549 and NCI-H446 cells was similar to that of Pris combined with Cis. These results confirmed that Pris enhanced Cis-induced apoptosis through inhibiting the AKT signaling pathways.

GSK $3 \beta$ is an important downstream target of AKT involved in regulating cell apoptosis $(44,45)$. It has been reported that Akt can inactivate GSK3 $\beta$ via the phosphorylation of Ser9 $(45,46)$. 
Therefore, the present study detected the phosphorylation of GSK3 $\beta$ at Ser 9 in A549 and NCI-H446 cells. Pris, Cis and the combination treatment mediated the dephosphorylation of GSK $3 \beta$. In addition, the combination treatment markedly inhibited the phosphorylation of GSK $3 \beta$ at Ser 9 compared with either drug alone. Notably, treatment of the cells with LY294002 alone markedly attenuated the phosphorylation of GSK3 $\beta$ at Ser 9. It was also observed that the combination treatment of Pris and Cis markedly inhibited the phosphorylation of Akt and GSK3 $\beta$ compared with either drug alone in vivo. Therefore, these results indicated that Pris may enhance Cis-induced apoptosis through inhibiting AKT/GSK3 $\beta$ signaling. Additional studies have demonstrated that miRs are associated with apoptosis in a variety of cancer cells (47-49). In the present study, it was observed that Pris significantly downregulated the expression level of miR-23a in A549 and NCI-H446 cells. Han et al (24) reported that the inhibition of miR-23a enhanced erlotinib-mediated lung cancer stem cell apoptosis through the PTEN/PI3K/AKT signaling (24). To confirm the association between miR-23a and PTEN/AKT signaling, western blotting was performed in the present study and the results demonstrated that the downregulation of miR-23a markedly increased the expression of PTEN, but decreased the expression of p-AKT. In addition, the effect of Cis combined with the miR-23a inhibitor on the apoptosis of A549 and NCI-H446 cells was similar to that of Pris combined with Cis. Taken together, these data indicated that Pris enhanced the pro-apoptotic ability of Cis in A549 and NCI-H446 cells through inhibiting miR-23a/PTEN/Akt signaling.

Autophagy is often considered as type II-programmed cell death, which has a dual role in regulating the homeostasis of cells $(50,51)$. Increasing evidence suggests that autophagy induced by anticancer drugs can promote cell survival or autophagic cell death in various types of cancer (52-54). In the present study, the results demonstrated Pris markedly inhibited autophagy through downregulating the expression levels of LC3BII and beclin-1 in A549 and NCI-H446 cells. To confirm whether autophagy was involved in cell apoptosis, the A549 and NCI-H446 cells were treated with 3-MA and Cis. The results showed that inhibiting autophagy significantly enhanced Cis-mediated cell apoptosis. These results indicated that Pris enhanced Cis-induced apoptosis in A549 and NCI-H446 cells through inhibiting autophagy.

In conclusion, the results of the present study showed that the combination of Cis and Pris synergistically inhibited cell proliferation, induced cell cycle arrest and promoted apoptosis in A549 and NCI-H446 cells. The findings indicated that Pris enhanced the sensitivity of A549 and NCI-H446 cells to Cis through inhibiting miR-23a/Akt/GSK3 $\beta$ signaling and suppressing autophagy. Therefore, these observations indicate that the combination of Cis and Pris may be a potential therapeutic strategy for overcoming lung cancer.

\section{Acknowledgements}

Not applicable.

\section{Funding}

The present study was supported by grants from the Shaanxi National Science Foundation (grant no. 2011JM4037), the
Scientific Research Program Funded by Shaanxi Provincial Education Department (grant no. 16JK1761) and the National Key Research and Development Program (grant no. 2016YFC0905001).

\section{Availability of data and materials}

The datasets used and/or analyzed in the present study are available from the corresponding author on reasonable request.

\section{Authors' contributions}

YZ and JW conducted the experiments and analyzed the data. LS made substantial contributions to the design of the study and prepared the manuscript. BH, WS, BL, FS, SC and LC performed the western blotting and analyzed the data. All authors read and approved the final manuscript.

\section{Ethics approval and consent to participate}

The experiments were approved by the Laboratory Animal Care Committee of Xi'an Jiaotong University (approval no. XJTULAC2018-527).

\section{Patient consent for publication}

Not applicable.

\section{Conflict of interests}

The authors declare that they have no competing interests.

\section{References}

1. Siegel RL, Miller KD and Jemal A: Cancer statistics, 2016. CA Cancer J Clin 66: 7-30, 2016.

2. Miller KD, Siegel RL, Lin CC, Mariotto AB, Kramer JL, Rowland JH, Stein KD, Alteri R and Jemal A: Cancer treatment and survivorship statistics, 2016. CA Cancer J Clin 66: 271-289, 2016.

3. Olaussen KA, Dunant A, Fouret P, Brambilla E, Andre F, Haddad V, Taranchon E, Filipits M, Pirker R, Popper HH, et al: DNA repair by ERCC1 in non-small-cell lung cancer and cisplatin-based adjuvant chemotherapy. N Engl J Med 355: 983-991, 2006.

4. Costa PM, Ferreira PM, Bolzani Vda S, Furlan M, de Freitas Formenton Macedo Dos Santos VA, Corsino J, de Moraes MO, Costa-Lotufo LV, Montenegro RC and Pessoa C: Antiproliferative activity of pristimerin isolated from Maytenus ilicifolia (Celastraceae) in human HL-60 cells. Toxicol In Vitro 22: 854-863, 2008.

5. Tu Y, Tan F, Zhou J and Pan J: Pristimerin targeting NF-кB pathway inhibits proliferation, migration, and invasion in esophageal squamous cell carcinoma cells. Cell Biochem Funct 36: 228-240, 2018.

6. Yousef BA, Hassan HM, Zhang LY and Jiang ZZ: Pristimerin exhibits in vitro and in vivo anticancer activities through inhibition of nuclear factor-small ka, CyrillicB signaling pathway in colorectal cancer cells. Phytomedicine 40: 140-147, 2018.

7. Cevatemre B, Erkisa M, Aztopal N, Karakas D, Alper P, Tsimplouli C, Sereti E, Dimas K, Armutak EII, Gurevin EG, et al: A promising natural product, pristimerin, results in cytotoxicity against breast cancer stem cells in vitro and xenografts in vivo through apoptosis and an incomplete autopaghy in breast cancer. Pharmacol Res 129: 500-514, 2018.

8. Liu YB, Gao X, Deeb D, Arbab AS and Gautam SC: Pristimerin induces apoptosis in prostate cancer cells by down-regulating Bcl-2 through ROS-dependent ubiquitin-proteasomal degradation pathway. J Carcinog Mutagen (Suppl 6): 005, 2013. 
9. Zhang B, Zhang J and Pan J: Pristimerin effectively inhibits the malignant phenotypes of uveal melanoma cells by targeting NFkappaB pathway. Int J Oncol 51: 887-898, 2017.

10. Deeb D, Gao X, Liu Y, Pindolia K and Gautam SC: Inhibition of hTERT/telomerase contributes to the antitumor activity of pristimerin in pancreatic ductal adenocarcinoma cells. Oncol Rep 34: 518-524, 2015.

11. Gao X, Liu Y, Deeb D, Arbab AS and Gautam SC: Anticancer activity of pristimerin in ovarian carcinoma cells is mediated through the inhibition of prosurvival Akt/NF-kappaB/mTOR signaling. J Exp Ther Oncol 10: 275-283, 2014.

12. Yan YY, Bai JP, Xie Y, Yu JZ and Ma CG: The triterpenoid pristimerin induces U87 glioma cell apoptosis through reactive oxygen species-mediated mitochondrial dysfunction. Oncol Lett 5: 242-248, 2013.

13. Chang FR, Hayashi K, Chen IH,Liaw CC, Bastow KF, Nakanishi Y, Nozaki H, Cragg GM, Wu YC and Lee KH: Antitumor agents. 228. five new agarofurans, Reissantins A-E, and cytotoxic principles from Reissantia buchananii. J Nat Prod 66: 1416-1420, 2003.

14. Park JH and Kim JK: Pristimerin, a naturally occurring triterpenoid, attenuates tumorigenesis in experimental colitis-associated colon cancer. Phytomedicine 42: 164-171, 2018.

15. Yousef BA, Guerram M, Hassan HM, Hamdi AM, Zhang LY and Jiang ZZ: Pristimerin demonstrates anticancer potential in colorectal cancer cells by inducing G1 phase arrest and apoptosis and suppressing various pro-survival signaling proteins. Oncol Rep 35: 1091-1100, 2016.

16. Wu CC, Chan ML, Chen WY, Tsai CY, Chang FR and Wu YC: Pristimerin induces caspase-dependent apoptosis in MDA-MB-231 cells via direct effects on mitochondria. Mol Cancer Ther 4 1277-1285, 2005.

17. Wang Y, Zhou Y, Zhou H, Jia G, Liu J, Han B, Cheng Z, Jiang H, Pan S and Sun B: Pristimerin causes G1 arrest, induces apoptosis, and enhances the chemosensitivity to gemcitabine in pancreatic cancer cells. PLoS One 7: e43826, 2012.

18. Xie G, Yu X, Liang H, Chen J, Tang X, Wu S and Liao C: Pristimerin overcomes adriamycin resistance in breast cancer cells through suppressing Akt signaling. Oncol Lett 11: 3111-3116, 2016.

19. Livak KJ and Schmittgen TD: Analysis of relative gene expression data using real-time quantitative PCR and the 2(-Delta Delta C(T)) method. Methods 25: 402-408, 2001.

20. Zhang K, Xu H, Jia X, Chen Y, Ma M, Sun L and Chen H: Ultrasound-triggered nitric oxide release platform based on energy transformation for targeted inhibition of pancreatic tumor. ACS Nano 10: 10816-10828, 2016.

21. Zhang K, Li P, He Y, Bo X, Li X, Li D, Chen $\mathrm{H}$ and $\mathrm{Xu} \mathrm{H}$ Synergistic retention strategy of RGD active targeting and radiofrequency-enhanced permeability for intensified RF \& chemotherapy synergistic tumor treatment. Biomaterials 99: 34-46, 2016.

22. Zhang K, Li P, Chen H, Bo X, Li X and Xu H: Continuous cavitation designed for enhancing radiofrequency ablation via a special radiofrequency solidoid vaporization process. ACS Nano 10: $2549-2558,2016$

23. Jung D, Khurana A, Roy D, Kalogera E, Bakkum-Gamez J, Chien J and Shridhar V: Quinacrine upregulates p21/p27 independent of p53 through autophagy-mediated downregulation of p62-Skp2 axis in ovarian cancer. Sci Rep 8: 2487, 2018.

24. Han Z, Zhou X, Li S, Qin Y, Chen Y and Liu H: Inhibition of miR-23a increases the sensitivity of lung cancer stem cells to erlotinib through PTEN/PI3K/Akt pathway. Oncol Rep 38: 3064-3070, 2017.

25. Li ZW, Zhao L, Han QC and Zhu X: CXCL13 inhibits microRNA-23a through PI3K/AKT signaling pathway in adipose tissue derived-mesenchymal stem cells. Biomed Pharmacother 83: 876-880, 2016.

26. Wu X, Xue X, Wang L, Wang W, Han J, Sun X, Zhang H, Liu Y, Che X, Yang J and Wu C: Suppressing autophagy enhances disulfiram/copper-induced apoptosis in non-small cell lung cancer. Eur J Pharmacol 827: 1-12, 2018.

27. Han C, Xing G, Zhang M, Zhong M, Han Z, He C and Liu X: Wogonoside inhibits cell growth and induces mitochondrialmediated autophagy-related apoptosis in human colon cancer cells through the PI3K/AKT/mTOR/p70S6K signaling pathway. Oncol Lett 15: 4463-4470, 2018.

28. Sun CY, Zhu Y, Li XF, Wang XQ, Tang LP, Su ZQ, Li CY, Zheng GJ and Feng B: Scutellarin increases cisplatin-induced apoptosis and autophagy to overcome cisplatin resistance in non-small cell lung cancer via ERK/p53 and c-met/AKT signaling pathways. Front Pharmacol 9: 92, 2018.
29. Czarnomysy R, Surazynski A, Muszynska A, Gornowicz A, Bielawska A and Bielawski K: A novel series of pyrazole-platinum(II) complexes as potential anti-cancer agents that induce cell cycle arrest and apoptosis in breast cancer cells. J Enzyme Inhib Med Chem 33: 1006-1023, 2018.

30. Ling Z, Guan H, You Z, Wang C, Hu L, Zhang L, Wang Y, Chen S, Xu B and Chen M: Aloperine executes antitumor effects through the induction of apoptosis and cell cycle arrest in prostate cancer in vitro and in vivo. Onco Targets Ther 11: 2735-2743, 2018.

31. Ahmad M, Hahn IF and Chatterjee S: GRP78 up-regulation leads to hypersensitization to cisplatin in A549 lung cancer cells. Anticancer Res 34: 3493-3500, 2014

32. Sivalingam KS, Paramasivan P, Weng CF and Viswanadha VP: Neferine potentiates the antitumor effect of cisplatin in human lung adenocarcinoma cells via a mitochondria-mediated apoptosis pathway. J Cell Biochem 118: 2865-2876, 2017.

33. Wang LS, Chen SJ, Zhang JF, Liu MN, Zheng JH and Yao XD: Anti-proliferative potential of Glucosamine in renal cancer cells via inducing cell cycle arrest at G0/G1 phase. BMC Urol 17: 38 , 2017.

34. Chen SH, Gong X, Zhang Y, Van Horn RD, Yin T, Huber L, Burke TF, Manro J, Iversen PW, Wu W, et al: RAF inhibitor LY3009120 sensitizes RAS or BRAF mutant cancer to CDK4/6 inhibition by abemaciclib via superior inhibition of phospho-RB and suppression of cyclin D1. Oncogene 37: 821-832, 2018.

35. Stivala LA, Cazzalini O and Prosperi E: The cyclin-dependent kinase inhibitor p21CDKN1A as a target of anti-cancer drugs. Curr Cancer Drug Targets 12: 85-96, 2012.

36. Starostina NG and Kipreos ET: Multiple degradation pathways regulate versatile CIP/KIP CDK inhibitors. Trends Cell Biol 22: 33-41, 2012.

37. Kelly PN and Strasser A: The role of Bcl-2 and its pro-survival relatives in tumourigenesis and cancer therapy. Cell Death Differ 18: 1414-1424, 2011.

38. Yang H, Landis-Piwowar KR, Lu D, Yuan P, Li L, Reddy GP, Yuan X and Dou QP: Pristimerin induces apoptosis by targeting the proteasome in prostate cancer cells. J Cell Biochem 103: 234-244, 2008

39. Liu D, You P, Luo Y, Yang M and Liu Y: Galangin Induces Apoptosis in MCF-7 human breast cancer cells through mitochondrial pathway and phosphatidylinositol 3-Kinase/Akt Inhibition. Pharmacology 102: 58-66, 2018.

40. Lin W, Xie J, Xu N, Huang L, Xu A, Li H, Li C, Gao Y, Watanabe M, Liu C and Huang P: Glaucocalyxin A induces G2/M cell cycle arrest and apoptosis through the PI3K/Akt pathway in human bladder cancer cells. Int J Biol Sci 14: 418-426, 2018

41. Deeb D, Gao X, Liu YB, Pindolia K and Gautam SC: Pristimerin, a quinonemethide triterpenoid, induces apoptosis in pancreatic cancer cells through the inhibition of pro-survival $\mathrm{Akt} / \mathrm{NF}-\mathrm{\kappa B} / \mathrm{mTOR}$ signaling proteins and anti-apoptotic Bcl-2. Int J Oncol 44: 1707-1715, 2014

42. Bi T, Zhu A, Yang X, Qiao H, Tang J, Liu Y and Lv R: Metformin synergistically enhances antitumor activity of cisplatin in gallbladder cancer via the PI3K/AKT/ERK pathway. Cytotechnology 70: 439-448, 2018.

43. Liao XZ, Tao LT, Liu JH, Gu YY, Xie J, Chen Y, Lin MG, Liu TL, Wang DM, Guo HY and Mo SL: Matrine combined with cisplatin synergistically inhibited urothelial bladder cancer cells via down-regulating VEGF/PI3K/Akt signaling pathway. Cancer Cell Int 17: 124, 2017.

44. Zhang R, Li G, Zhang Q, Tang Q, Huang J, Hu C, Liu Y, Wang Q, Liu W, Gao N and Zhou S: Hirsutine induces mPTP-dependent apoptosis through ROCK1/PTEN/PI3K/GSK $3 \beta$ pathway in human lung cancer cells. Cell Death Dis 9: 598, 2018.

45. Xue M, Ji X, Xue C, Liang H, Ge Y, He X, Zhang L, Bian K and Zhang L: Caspase-dependent and caspase-independent induction of apoptosis in breast cancer by fucoidan via the PI3K/AKT/GSK $3 \beta$ pathway in vivo and in vitro. Biomed Pharmacother 94: 898-908, 2017.

46. Wang Y, Zhao M, Liu J, Sun Z, Ni J and Liu H: miRNA-125b regulates apoptosis of human non-small cell lung cancer via the PI3K/Akt/GSK3 $\beta$ signaling pathway. Oncol Rep 38: 1715-1723, 2017.

47. Li Z, Lin C, Zhao L, Zhou L, Pan X, Quan J, Peng X, Li W, Li H, $\mathrm{Xu} \mathrm{J}$, et al: Oncogene miR-187-5p is associated with cellular proliferation, migration, invasion, apoptosis and an increased risk of recurrence in bladder cancer. Biomed Pharmacother 105: $461-469,2018$ 
48. Hu X, Wang Y, Liang H, Fan Q, Zhu R, Cui J, Zhang W, Zen K, Zhang CY, Hou D, et al: miR-23a/b promote tumor growth and suppress apoptosis by targeting PDCD4 in gastric cancer. Cell Death Dis 8: e3059, 2017.

49. Farooqi AA, Qureshi MZ, Coskunpinar E, Naqvi SK, Yaylim I and Ismail M: MiR-421, miR-155 and miR-650: Emerging trends of regulation of cancer and apoptosis. Asian Pac J Cancer Prev 15: 1909-1912, 2014

50. Ryter SW, Mizumura K and Choi AM: The impact of autophagy on cell death modalities. Int J Cell Biol 2014: 502676, 2014.

51. Keta O, Bulat T, Golic I, Incerti S, Korac A, Petrovic I and Ristic-Fira A: The impact of autophagy on cell death modalities in CRL-5876 lung adenocarcinoma cells after their exposure to gamma-rays and/or erlotinib. Cell Biol Toxicol 32: 83-101, 2016.

52. Cheng X, Feng H, Wu H, Jin Z, Shen X, Kuang J, Huo Z, Chen X, Gao H, Ye F, et al: Targeting autophagy enhances apatinib-induced apoptosis via endoplasmic reticulum stress for human colorectal cancer. Cancer Lett 431: 105-114, 2018.
53. Bai XY, Liu YG, Song W, Li YY, Hou DS, Luo HM and Liu P: Anticancer activity of tetrandrine by inducing pro-death apoptosis and autophagy in human gastric cancer cells. J Pharm Pharmacol 70: 1048-1058, 2018.

54. Yu X, Lin H, Wang Y, Lv W, Zhang S, Qian Y, Deng X, Feng N, $\mathrm{Yu} \mathrm{H}$ and Qian B: d-limonene exhibits antitumor activity by inducing autophagy and apoptosis in lung cancer. Onco Targets Ther 11: 1833-1847, 2018.

(i) (9) This work is licensed under a Creative Commons Attribution-NonCommercial-NoDerivatives 4.0 International (CC BY-NC-ND 4.0) License. 